\title{
Mudanças estruturais e ensino de jornalismo: o papel do professor nos novos rumos do jornalismo brasileiro
}

\section{Rafael Pereira da Silva}

Mestre; Universidade Federal de Juiz de Fora

domrafasil@gmail.com

\section{Boanerges Balbino Lopes}

Doutor; Universidade Federal de Juiz de Fora bblopes@globo.com

\section{Resumo}

o jornalismo contemporâneo é reconfigurado por transformações na produção e a veiculação das notícias, em paralelo, temos a integração tecnológica e a convergência midiática. Simultaneamente, temos um alargamento do campo entrelaçando atividades e competências dos profissionais. Destarte, o artigo reflete sobre os desafios e o papel dos professores e dos cursos de jornalismo neste cenário. Como metodologia, utilizamos uma revisão de literatura baseada nos estudos sobre o ethos e o habitus jornalístico sob a ótica de Traquina, Bourdieu e Cavalcanti, associada a um suporte de entrevistas realizadas entre 2011 e 2014 com dois grupos de jornalistas, um deles ligado à midia tradicional e o outro às assessorias de imprensa. Entre as considerações, destaca-se a necessidade de se pensar, ensinar e praticar jornalismo de maneira consciente, evitando-se as lacunas entre os aspectos acadêmicos e mercadológicos e estimulando o fomento à percepção evidenciada pelas múltiplas identidades do jornalista contemporâneo, envolto em habilidades e competências diversificadas.

\section{Palavras-chave}

Ensino. Jornalismo. Ethos. Habitus. 


\section{Introdução}

Há pelo menos 20 anos tem-se verificado uma grande transformação no campo profissional do jornalismo, em seu saber-fazer e, como consequência, no ensino de jornalismo no Brasil. Readequar-se às novas demandas e necessidades do mercado de notícias e da sociedade de forma geral foi uma condição básica para o avanço. Com a introdução das novas tecnologias da comunicação nas redações, a partir da década de 1980, computadores e internet revolucionaram o mundo do trabalho. 0 quadro de modificações que até então se desenvolvia em um ritmo não tão acelerado, passou a alterar-se significativamente, interferindo não só na rotina, mas também no modo de produção, veiculação, consumo e no discurso do próprio jornalista sobre sua profissão.

0 que se percebe hoje está relacionado com a mutação que incide sobre as organizações informativas, o ensino de jornalismo e o campo da comunicação. No geral, observa-se a modificação da cultura da profissão - do legs'man (o homem das pernas, o repórter que gasta sola de sapato) do passado ao "jornalista sentado" (das redações multimídia). A transformação tem alterado as habilidades e competências exigidas aos profissionais que ingressam no mercado a cada ano. Daí tem-se uma relação de causa e efeito, onde as alterações no mundo profissional afetam diretamente as pesquisas e as metodologias de ensino de jornalismo.

Todavia, as mudanças de ordem tecnológica não são os únicos fatores que implicam em uma considerada "crise" do jornalismo contemporâneo. A queda do diploma universitário em 17 de junho de 2009, por decisão do Supremo Tribunal Federal, pode ser vislumbrada como uma ruptura nos marcos e fronteiras que balizam a identidade profissional do jornalista brasileiro. Implementado durante o regime militar, há pelo menos 40 anos, desde sua instituição obrigatória por meio do decreto-lei 972 de 1969 (BRASIL, 1969), o diploma oferecia o capital simbólico que estabelecia e afirmava a diferenciação identitária desta profissão.

Recentemente, os debates no mundo do jornalismo colocam a questão do ensino em posição de destaque: as discussões nesta área tem se pautado pela adoção e implementação das Novas Diretrizes Curriculares do Jornalismo (BRASIL, 2013), que trouxeram à pauta acadêmica o antigo confronto entre teoria e prática. Na visão de alguns pesquisadores como Marcondes Filho (2014), em entrevista à Revista Cult, as Novas Diretrizes estabelecem uma desvinculação na formação do jornalista da cultura científica e humanística da área de 
comunicação. De outro modo, as diretrizes impõem cada vez mais, um domínio técnico e uma aproximação com o mercado profissional. Teríamos assim um mal necessário?

Neste trabalho, será feita outra abordagem com o objetivo de contribuir de maneira mais acentuada com a prática de ensino e aprendizagem: discutir a importância de se compreender a identidade profissional do jornalista contemporâneo e as mudanças estruturais na profissão como estratégias metodológicas para o ensino do jornalismo no Brasil.

\section{Mudanças estruturais no campo do jornalismo}

Com o objetivo de analisar as modificações estruturais no campo do jornalismo, foram adotadas as formulações do sociólogo Pierre Bourdieu e sua noção de campo aparato conceitual para apreender e refletir sobre o jornalismo como lugar de estudos, pesquisas acadêmicas e saber profissional. A noção de campo, segundo o autor, pode ser entendida como um espaço social estruturado que possui autonomia relativa e leis próprias. Esses microcosmos da sociedade, na concepção de Bourdieu (2012), caracterizar-se-iam por agentes dotados de um mesmo habitus - os jornalistas -, onde o campo estrutura o habitus e o mesmo constitui o campo em uma relação recíproca. Assim, ao compreender o jornalismo como campo é preciso ter em mente que esta esfera social abarca múltiplas dimensionalidades, ou seja, possui vários agentes e instituições envolvidos. Lopes (2000), ao realizar uma reflexão sobre o estatuto disciplinar da comunicação, propõe uma definição formal e abrangente do que seja, a princípio, o campo acadêmico. A pesquisadora brasileira o especifica como:

[...] um conjunto de instituições de nível superior destinado ao estudo e ao ensino da comunicação e onde se produz a teoria, a pesquisa e a formação universitária das profissões de comunicação. Isso implica dizer que nesse campo podem ser identificados vários subcampos: 1) o científico, que implica em práticas de produção de conhecimento: a pesquisa acadêmica tem a finalidade de produzir conhecimento teórico e aplicado (ciência básica e aplicada) através da construção de objetos, metodologias e teorias; 2) o educativo, que se define por práticas de reprodução desse conhecimento, ou seja, através do ensino universitário de matérias ditas de comunicação; e 3) o profissional, caracterizado por práticas de aplicação do conhecimento e que promove vínculos variados com o mercado de trabalho. (LOPES, 2000, p. 42).

A existência de um campo e de seus limites pode ser também determinada pelos interesses específicos, pelos investimentos feitos pelos agentes dotados de um habitus e 
pelas instituições - empresas de comunicação, sindicatos, instituições de ensino em jornalismo, etc. Este campo, como argumenta Bourdieu (2012), está em constante processo de estruturação, reformulação e permanentemente envolvido em conflito. Para o sociólogo, estes espaços são constituídos por uma rede de relações que são feitas entre os diversos agentes sociais, como também pelos diferentes arcabouços.

Um campo é um espaço social estruturado, um campo de forças - há dominantes e dominados, há relações constantes, permanentes, de desigualdade, que se exercem no interior desse espaço - que é também um campo de lutas para transformar ou conservar este campo de forças. Cada um, no interior desse universo, empenha em sua concorrência com os outros a força (relativa) que detém e que define sua posição no campo e, em conseqüência, suas estratégias. (BOURDIEU, 1997, p. 57).

No campo do jornalismo os processos de midiatização ${ }^{1}$ e a cultura da convergência, fenômenos socioculturais contemporâneos têm provocado uma metamorfose nas práticas e nos paradigmas dessa profissão secular, promovendo uma verdadeira "reviravolta do saber" profissional e acadêmica. Este processo tem se intensificado nos últimos 15 ou 20 anos, provocando transformações em sua natureza; nas identidades profissionais; na circulação e consumo dos produtos midiáticos e, em especial, nos jornalistas, agentes dotados de um habitus específico.

A Internet implica não só numa participação ativa da audiência na seleção e processamento da mensagem, mas também na participação ativa em sua criação. [...] Os emissores tradicionais da mensagem, neste caso, os jornalistas, confrontam-se não só com um novo método de entrega, como também estão diante de uma nova mudança fundamental em seu papel dentro do processo comunicativo. (SINGER, 1998, p. 2 apud OLIVEIRA, 2001, p. 107).

Contudo, é preciso lembrar que evoluções e transformações das práticas jornalísticas são recorrentes. Na década de 1950, por exemplo, tem-se a profissionalização do setor com a adoção de padrões técnicos, éticos e estilísticos, onde critérios como objetividade, neutralidade surgem no cenário brasileiro advindas do jornalismo norteamericano, e tem-se o enraizamento de práticas próprias como o lead e a pirâmide invertida que se tornam o modelo padrão da atividade. Esse conjunto de mudanças ocorridas no jornalismo e o início do ensino universitário no Brasil constituem o primeiro grande conjunto de mudanças estruturais no campo específico, e consequentemente sobre o

\footnotetext{
1 Compreendemos que a midiatização é um fenômeno contemporâneo, onde os meios de comunicação exercem impacto significativo sobre a sociedade contemporânea e a interação entre os indivíduos.
} 
modelo que se aplica nas escolas. Como destaca Jauranice Cavalcanti (2006) em análise sobre o ethos discursivo dos jornalistas:

O jornalista romântico passa a ser visto como ineficaz despreparado para enfrentar as crescentes mudanças, como a racionalização dos processos de produção. Isso não significa que há puramente uma substituição, sai de cena o romântico e entra o racional, o metódico, mas que novas discursividades se abrem, possibilitando, assim, que novos elementos entrem na configuração do imaginário do/sobre o jornalista, na constituição de sua identidade. (CAVALCANTI, 2006, p. 70).

A partir das instâncias artísticas e intelectuais, os novos habitus do jornalismo brasileiro ganham força e gradativamente firmam um campo propriamente dito. Uma nova ideologia, baseada em práticas objetivas na busca pela verdade dos fatos e na adoção de princípios reguladores das atividades cotidianas da profissão, deu suporte para a emergência de uma cultura e de um ethos profissional e ambos passam a exercer influência sobre a construção das notícias.

Na década de 1980, a revolução ocorreu na sistematização das estruturas organizacionais das empresas jornalísticas. Elas se transformaram e passaram a investir em padrões de gestão que exigissem uma reestruturação dos modos de administrar uma redação, interferindo inclusive nos processos de admissão e formação de novos profissionais jornalistas.

Para o ensino do jornalismo via universidade, iniciado em meados da década de 50 e consolidado com a instituição do diploma, em 1969, a implementação de novos padrões ético-morais e adoção de critérios técnicos importados do moderno norte-americano de jornalismo, e mais as modificações nas redações a partir da década de 1980, representaram, certamente, grandes desafios ao ensino da profissão. Além de transmitir um saber prático sobre como fazer, era necessário legar valores emanados do novo pólo ideológico que se constituía, emanado por um estatuto profissional consolidado.

Para Traquina (2008, p.23) o processo de profissionalização leva à formação de grupos organizados, “[...] dependentes de uma solidariedade cerrada e dependente de seus membros para constituírem um grupo à parte com um ethos próprio [...]” (HUGHES, 1963, p. 657). Esse processo, segundo o pesquisador português, que cita Greenwood (1957), leva à criação de uma cultura que requer ajustamentos como pré-requisitos para o sucesso na carreira. Tal propriedade é, para Greenwood, o atributo mais importante de uma profissão, e consiste na formação de valores, normas e preceitos sociais para esses profissionais. 
Abordar mudanças estruturais no jornalismo e suas relações com as identidades dos profissionais da notícia implica, antes de tudo, em situá-lo como uma prática social, marcada por um processo de reinvenção permanente, (re)construído a partir da participação contínua de diferentes atores sociais (indivíduos, instituições, conceitos e abstrações etc.) que interagem tendo como base um conjunto de normas e convenções, responsáveis pela coordenação das atividades vinculadas a essa prática.

Para que uma mudança seja considerada estrutural é preciso, portanto, que ela seja suficientemente abrangente e profunda para alterar radicalmente o modo como determinada atividade é praticada e simbolicamente reconhecida/definida pelos atores. Ou seja, uma mudança estrutural se contrapõe a um grupo de mudanças conjunturais e também as microinovações que normalmente afetam aspectos específicos de uma prática social. Por exemplo, o lançamento de um novo jornal ou introdução de um novo software de diagramação certamente altera o modo como o jornalismo é praticado, mas dificilmente pode ser o estopim de um processo de mudanças estruturais. Por outro lado, o aparecimento de uma nova mídia - como a internet - ou uma crise generalizada nas empresas de comunicação oferece potencial para alterar uma dimensão mais profunda da pratica jornalística. (ADGHIRNI; PEREIRA, 2010, p. 42).

As mudanças que se apresentam determinaram adiante uma transformação singular nos currículos e na transmissão de conhecimento sobre o saber prático a respeito do jornalismo. De toda forma, é necessário ter em mente o reconhecimento em relação aos entraves na relação ensino e mercado, já que é praticamente impossível oferecer aos estudantes conhecimento especializado em tudo que eles vão realizar em suas atividades e carreiras profissionais.

\section{0 atual panorama sobre o mundo do jornalismo}

Mesmo que o jornalismo possua uma história concreta no tempo e no espaço e tenha se consolidado como uma das instituições sociais mais importantes do século XX, ainda hoje teóricos e investigadores em diversas áreas do conhecimento como Comunicação, Sociologia, e Antropologia, se perguntam sobre o que é ser jornalista. Quais seriam as fronteiras desta profissão? Qual é a identidade cultural desses agentes? Estes questionamentos têm direcionado uma série de incursões acadêmicas no mundo jornalístico da contemporaneidade. Em um momento de grandes transformações, compreender o que é ser jornalista, e qual o papel deste profissional na sociedade é imprescindível para fortalecer as práticas de ensino e aprendizagem. 
Ao analisar o contexto de expansão do campo profissional percebe-se um alargamento, constatado principalmente pela atuação de jornalistas em espaços outros que não as mídias tradicionais (impresso, rádio, TV, e agora a internet). Tem-se, desta forma, um cenário instável permeado por um contínuo mutacional que desencadeia uma dilatação das fronteiras, cujo ponto de equilíbrio ainda é uma questão que permanece em aberto. Segundo Rublesky e Silva (2012), trata-se de um movimento que amplia o campo jornalístico pelas tensões, continuidades, potencializações e descontinuidades que caracterizam este tipo de processo.

No Brasil, as mudanças estruturais têm promovido a expansão de um forte segmento de mídias institucionais, considerado por pesquisadores como alternativa imediata para jornalistas veteranos e mesmos os egressos das universidades. Trata-se ainda de um dos poucos setores que apresentam crescimento expressivo no mercado de trabalho brasileiro, conforme constatam Jacques Mick e Samuel Lima (2013) com a realização de uma pesquisa sobre o perfil do jornalista brasileiro:

Transformações estruturais do capitalismo combinaram-se à política de expansão do ensino superior, à redemocratização do país e às mudanças na regulamentação profissional e produziram um ambiente em que se configuraram por inteiro as possibilidades de atuação dos jornalistas. Como resultados, as dimensões da categoria se expandiram exponencialmente e alteraram-se competências e habilidades deles demandadas. (MICK; LIMA, 2013, p. 15).

O levantamento realizado por meio de uma ampla pesquisa, em 2012, apresenta os resultados de uma enquete em rede, de participação espontânea, com 2731 respostas. Os dados estimam que o total de jornalistas registrado no período compreendido entre 1980 e 2010 no Brasil seja de 145 mil, sendo que 01 (um) em cada 04 (quatro) jornalistas no país não tem registro profissional. Dos jornalistas brasileiros, 55\% trabalham atualmente nas mídias, ou seja, estão envolvidos com a produção de notícias em veículos clássicos, como jornais diários, revistas, telejornais ou rádio-jornais (MICK; LIMA, 2013). Já os profissionais que atuam fora da mídia, como assessores de imprensa ou comunicação ou em inúmeras outras funções, chegam a 40\% dos jornalistas brasileiros, sendo que deste universo, 68,3\% são contratados como assessores de imprensa ou comunicação.

Como aponta a pesquisa, a migração de profissionais dos meios de comunicação tradicionais para as mídias corporativas deve-se à precarização e ao "inchaço" das redações pelos profissionais que ingressam todos os anos no mercado de trabalho. Algumas dessas situações vivenciadas são expostas em outra pesquisa, realizada em São Paulo, que trata das 
mudanças no mundo do trabalho do jornalista. Conforme Figaro (2013), os desafios que os jornalistas enfrentam no exercício profissional são grandes: vínculos empregatícios precários, baixos salários, extensas jornadas de trabalho, exigências de atualização constante no uso de ferramentas digitais de prospecção, de apuração e edição, entre outros.

Outro fator fundamental para a apreensão que permeia o mundo dos jornalistas é o aumento na oferta de cursos superiores nos últimos 20 anos, o que tem provocado uma projeção quantitativa além da previsão numérica esperada na realidade recente de mercado, promovendo concorrência acirrada aos postos de trabalho. De acordo com (MICK; LIMA, 2013), até o final dos anos 1980, o país tinha poucos cursos de graduação em Comunicação Social, divididos entre as habilitações da área e fortemente concentradas em São Paulo e Rio de Janeiro. As políticas de expansão do ensino superior no país, desenvolvidas pelos governos Fernando Henrique Cardoso e Luiz Inácio Lula da Silva, têm alterado essa realidade. Nesse período, a investigação demonstra que o número de escolas de jornalismo cresceu continuamente: de 61 cursos em 1990, para 317, após 20 anos.

Quadro 1 - cursos de jornalismo com turmas abertas em 2010 no Brasil, por década de início do Curso.

\begin{tabular}{|l|r|r|r|r|r|}
\hline & \multicolumn{1}{|l|}{$\begin{array}{l}\text { Antes de } \\
1970\end{array}$} & Até 1980 & Até 1990 & \multicolumn{1}{|l|}{ Até 2000 } & \multicolumn{1}{|l|}{ Até 2010 } \\
\hline Total de cursos & 18 & 51 & 61 & 137 & 317 \\
\hline
\end{tabular}

Fonte: Perfil do Jornalista Brasileiro (MICK; LIMA, 2013)

Neste quadro, dada as singularidades do processo de constituição da comunicação organizacional no Brasil, o trabalho de assessoria de imprensa/comunicação tem sido considerado na prática uma esfera de atuação de jornalistas (SANT'ANNA, 2008). É preciso lembrar que, no Brasil, por negociação e consentimento dos conselhos e órgãos sindicais brasileiros, com destaque a Fenaj e o Conferp, há décadas os profissionais que atuam nas assessorias de imprensa, espaços antes ocupados por profissionais da área de relações públicas, foram absorvidos e dividem as atividades e funções nas empresas e instituições.

\section{A crise contemporânea do jornalismo e o trabalho fora das redações}

Com a crise das corporações midiáticas, acentuadamente dos veículos impressos, contata-se um deslocamento crescente dos jornalistas profissionais que passam a atuar em outros centros de produção, como em organizações no setor público, privado e do terceiro setor não tem na busca pela notícia imediata sua principal atribuição. É perceptível na 
atualidade que, entre jovens ingressantes na profissão, muitos nunca exerceram atividades em uma redação de jornal. 0 que tem sido propiciado pelo mercado hoje ampliado e que oferece alternativas envolvendo possibilidades que se configuram muito além daquelas tradicionais.

Somando-se a isto, o processo de reorganização e transição de posturas e condutas organizacionais nos indicam caminhos promissores para o entendimento da dinâmica interativa das organizações com a sociedade contemporânea. As organizações constituemse, afinal, como instâncias de articulação de interesses e objetivos dos mais variados atores, ou seja, fontes das mais diversas intenções e ações de indivíduos que, reunidos em prol de propósitos comuns e com recursos disponíveis, passam a intervir em contextos sociais, econômicos, políticos e culturais, como destacam Soares e Monteiro (2012, p. 50). As organizações têm nas estratégias de comunicação a sua principal ferramenta de diálogo com a mídia e com a sociedade e, por isso, se "apropriam" de profissionais da mídia e de suas técnicas.

As transições nos espaços e, consequentemente, no habitus profissional dos jornalistas implica em reflexões acerca do ensino desta profissão. Hoje não basta mais , saber produzir, apurar, redigir e editar uma matéria para os veículos de comunicação. Para este profissional multifacetado que ocupa espaços em outras searas que não o campo das mídias, torna-se necessário em sua formação adquirir outras habilidades, como gerenciar redes sociais, planejar ações, pensar estrategicamente.

A questão posta com certa ênfase aqui é se esse deslocamento estaria forjando uma nova identidade, a do jornalista-assessor, ou reafirmaria a identidade existente (sendo o trabalho executado fora das redações considerado como uma nova especialidade do próprio jornalista profissional). Lembramos que mesmo fora dos espaços tradicionais, as práticas e os conceitos daquilo que seria o "bom jornalismo" se manteriam nesses profissionais. Como é possível verificar, estamos em um ambiente fluido, cambiante, onde jornalismo midiático e extra-redação ${ }^{2}$ convergem e atuam juntos na produção dos noticiários cotidianos. Nesse panorama, jornalistas e jornalismo alteram-se, redefinem-se, reconfiguram seus papéis sociais e assumem novas funções. Por essa razão, justifica-se a premência em discutir sua identidade por uma perspectiva cultural.

\footnotetext{
2 Por jornalismo extra-midiático, nos referimos aqui ao trabalho executado pelos profissionais formados em jornalismo que atuam em assessoria de imprensa e assessoria de comunicação, que segundo o Perfil do Jornalista Brasileiro (MICK; JACQUES, 2013), chega a $40 \%$ destes profissionais.
} 
Para entendermos melhor essa transformação e o consequente deslocamento do ambiente redacional que tem se intensificado na contemporaneidade, recorreremos mais uma vez ao conceito de campo de Pierre Bourdieu (2012). Tal conceito é basal para a compreensão das relações entre agentes sociais em sua atividade ou profissão no que diz respeito aos valores e disputas de poder envolvidas e, também, para refletir sobre as práticas sociais como lugares de produção simbólica. Pretende-se com este conceito indicar que, ao deslocar-se dos meios de comunicação tradicional para atuar em outras empresas e organizações, ou seja, uma mudança de habitus, isso implicaria ao jornalista assumir outra posição de sujeito. No entanto, para alguns pesquisadores, como Ferreira e Carvalho (2011), as fronteiras entre os campos da comunicação e da informação no Brasil sempre desafiaram as demarcações mais tradicionais (ou os referenciais europeus) que os localizam como esferas distintas.

Como especifica Fernanda Lima Lopes (2009) em sua investigação sobre o processo de institucionalização do mercado noticioso e os significados para a construção da identidade do jornalista no Brasil,

0 trabalho jornalístico do assessor de imprensa impacta a construção da identidade jornalística no que tange à ampliação dos lócus em que os sentidos para a profissão são negociados com a sociedade. Quando um jornalista faz parte do quadro de funcionários de um sindicato de professores, ou de uma associação de magistrados, ou de uma fábrica de aço, ou de uma câmara municipal, inaugura-se uma convivência daquele com os mais variados atores sociais: educadores, juízes, metalúrgicos, vereadores [...] Estes, por sua vez, já não conhecem a profissão de jornalista apenas através dos meios de comunicação, mas também vão formando uma imagem desses profissionais a partir das representações e ações do jornalista que foi incorporado ao seu cotidiano; "o jornalista da casa", que faz as fotos dos eventos, que atualiza o site da empresa, que entrevista Fulano e Sicrano para o jornal da organização [...] (LOPES, 2009, p. 71).

O conjunto de mudanças que atinge o campo da comunicação, ou seja, o mercado de trabalho, e as práticas dos jornalistas que atuam nos meios de comunicação e nos ambientes organizacionais - seja em assessoria de imprensa/comunicação, ou com gestão de redes sociais (atividade que surge com o advento da internet) - estão alterando significativamente o ensino universitário. A questão, então, implica em saber, se os professores estão preparados para ensinar e lidar com as novas temáticas e formas de produção?

É preciso ter a noção que apenas uma aparência agradável, uma voz marcante ou um texto inconfundível por sua qualidade impecável já não não são mais requisitos suficientes para atuar como jornalista. Quanto mais dinâmico e instantâneo fica o jornalismo digital, 
mais complexas suas formas se apresentam. Além de integrar o leitor em sua pauta diária, o jornalista contemporâneo deve ter um leque amplo de habilidades, as quais jamais imaginou possuir. Para ele, o profissional da notícia deve, além de escrever um artigo de forma categórica e bem estruturada, saber programar uma página ou até mesmo editar conteúdos de um site na internet. A dedução minimamente lógica que se viabiliza é a de que o novo profissional deve ser versátil e polivalente.

\section{0 discurso dos jornalistas como exemplificação dos desafios}

A fim de elucidar os desafios que o mercado profissional impõe às instituições de ensino e aos professores de jornalismo, foram utilizadas como suporte entrevistas realizadas com dois grupos de jornalistas em ocasiões distintas. 0 Grupo 1, formado por jornalistas que atuam nos veículos tradicionais, jornal, rádio e televisão: As entrevistas foram realizadas em 2011, com o objetivo de compreender as dificuldades dos jornalistas em lidarem com as novas tecnologias da comunicação. 0 Grupo 2, constituído por jornalistas que atuam em assessoria de imprensa: Entrevistas realizadas em dezembro de 2014, com o intuito de identificar o ethos discursivo dos jornalistas que atuam em assessoria de imprensa. O que foi dito pelos jornalistas em seus discursos demonstra no conjunto, resumidamente, a necessidade dos jornalistas, hoje, desenvolverem novas competências e habilidades.

\subsection{Para os jornalistas do Grupo $1^{3}$}

A percepção sobre as transformações que o uso da internet tem provocado no conteúdo jornalístico e no cotidiano dentro das redações, bem como nas práticas de apuração e veiculação da notícia fez parte do conjunto de perguntas formuladas aos entrevistados. Os profissionais foram enumerados para auxiliar na sistematização das respostas. Seus nomes são citados inicialmente. Na sequência, prevalecerá a numeração estabelecida:

Saber utilizar as ferramentas propiciadas pelas novas tecnologias é fundamental para o jornalista contemporâneo. Segundo Flávia Lopes (repórter - entrevistada 1), falta preparação dos jornalistas para utilizarem essas novas tecnologias. "Não há disciplinas que os ensinem a montar planilhas ou a conhecer os sites que disponibilizam informações a

3 As entrevistas com os jornalistas do Grupo 1 foram realizadas em pesquisa em 2011, ver Silva (2012). 
serem tabuladas." Para Pablo Cordeiro (repórter - entrevistado 2) utilizar as novas ferramentas é uma necessidade que o mercado pede. Ele acredita que o profissional deve adquirir a expertise para saber utilizar os buscadores a seu favor e cruzar os dados com os diversos aplicativos. Para Ricardo Miranda (repórter - entrevistado 3) a dificuldade não está em utilizar as ferramentas de busca de dados na web, mas sim em cruzar e analisar a informação que chega: "Isso requer um conhecimento aprofundado da realidade, que ainda falta, principalmente aos recém-formados."

Além das ferramentas de busca de dados e informações como o Google e o Bing, é de suma importância que os jornalistas tenham uma ampla rede de informações e contatos na internet. Para isso a utilização das redes sociais é muito importante. A entrevistada 1 diz que as redes sociais são hoje fontes inesgotáveis de pautas: “Com um clique é possível encontrar personagens para matérias, avaliar tendências e também medir feedback de conteúdos publicados pelos veículos.". No entanto, ela acredita que as redações ainda estão sem critérios definidos para a utilização dessas ferramentas.

Segundo o entrevistado 3, as redes sociais vêm exercendo um papel interessante, particularmente no processo de apuração. Mas essa influência ainda não pode ser mensurada: "Como é novidade, é necessário aguardar se vai se manter ou não. Mas é preciso ter cuidado: declarações no Twitter e Facebook são frias."

\subsection{Para os jornalistas do Grupo $2^{4}$}

Perguntados sobre as competências exigidas aos jornalistas que ocupam espaços em assessorias de comunicação e imprensa, os jornalistas-assessores responderam o seguinte. Aos entrevistados deste grupo foram atribuídas letras em sequência. Doravante, assim serão denominados :

Para Zilvan Martins (assessor A) “O assessor de comunicação também tem esse papel, o de ser um profissional misto, e tem que entender um pouco de administração, tem que ter noções de direito, porque ele está ali não só para ser um fazedor de release, ele está ali para orientar o seu assessorado, montar estratégias diferentes.". Ainda segundo o assesor A, o profissional deve pensar em todas as estratégias de divulgação e planejamento de uma matéria ou campanha.

\footnotetext{
4 As entrevistas com os jornalistas do Grupo 2 foram realizadas em pesquisa durante o ano de 2014, ver Silva (2015).
} 
De acordo com Maurício Lara (assessor B), trabalhar com assessoria de comunicação implica se envolver com outras áreas da comunicação, como a publicidade e as relações públicas. Outra entrevistada, Vilma Tomaz (assessora C), diz não ter sido preparada em sua formação para atuar no segmento: "Eu não tive formação acadêmica para ser jornalista em assessoria de comunicação, minha trajetória foi toda direcionada aos veículos.", o que ainda ocorre em muitos cursos de jornalismo que não estão preparados para as novas demandas do mercado profissional. Ainda na opinião da assessora $\mathrm{C}$, do especialista em comunicação é exigido muito mais do que o jornalista de veículo: "Fazemos não só atividades exclusivas do jornalismo como de repente nos envolvemos em produzir um texto de discurso. É preciso ser polivalente.".

Segundo João Carlos Firpe (asssessor D), a assessoria acaba tendo uma função mais ampla: "Dependendo da instituição é preciso tratar de outras áreas: publicidade, às vezes relações públicas, cerimonial, promoção de evento, atendimento a imprensa, comunicação interna, ações de comunicação externa. Então é muito mais diversificado. É mais complexo, um profissional mais completo do que na redação, onde só se tem funções práticas.".

Nos dois grupos, foram verificados por meio dos discursos dos jornalistas as lacunas que ainda precisam ser preenchidas pelo ensino universitário: primeiramente a utilização de novos tecnologias e sua adequação à pratica diária do jornalismo, e em segundo lugar a necessidade de possuir domínios que não são restritos ao profissional de jornalismo. Assim, é possível deduzir que cada vez mais torna-se necessário aos profissionais o domínio de um conhecimento amplo das técnicas de outros campos da comunicação, como a publicidade e as relações públicas. Com a implementação das Novas Diretrizes Curriculares do Jornalismo (BRASIL, 2013), na opinião dos profissionais, a possibilidade de que os cursos definam perfis mais técnicos se acentuou, pois eles estarão direcionados para as questões práticas do jornalismo. No entanto, o que pode ser percebido paradoxalmente, é que o mercado necessita de um profissional com uma visão ampla e não só da técnica operacional do jornalismo.

Outro fator importante a ser destacado relaciona-se ao período entre a realização das duas sequências de entrevistas: os jornalistas que atuavam no Grupo 1 deixaram de desenvolver atividades jornalísticas tradicionais. Dois deles tornaram-se assessores de imprensa, e um deles abandonou a carreira. 


\section{Considerações finais}

Os depoimentos dos jornalistas que atuam no dia a dia das redações produzindo notícias para os veículos de comunicação: jornais, tevês e rádios, e dos jornalistas que exercem a atividades de assessoria de imprensa/comunicação são sintomáticos e expõem os desafios que os professores de jornalismo tem para os próximos anos.

É preciso criar procedimentos, disciplinas, metodologias de ensino e aprendizado e processos pedagógicos que levem em conta essa natureza fluída do jornalismo contemporâneo. Ou seja, que evidencie o declínio do Jornalismo tradicional, e principalmente o papel dos meios de comunicação como instituições não mais as únicas mediadoras de informações perante a sociedade. Na nova dinâmica, jornais, rádios, tvs, portais e sites, blogues etc, juntam-se às outras tantas instituições como Estado, Igreja, escola ou mesmo família como produtoras e fomentadoras das informações que circulam; e que levem em conta o jornalismo enquanto prática social, inserida em diferentes contextos de produção, onde o presente é particularmente marcado pela ruptura dos limites espaciais e temporais que caracterizavam as experiências jornalísticas na modernidade.

Além da contextualização do cenário, atitude primordial para nortear racionalmente a atividade pedagógica, faz-se premente a redequação dos professores às necessidades da nova lógica produtiva. Assim, compreendemos que apenas fazer estudos, pesquisas e análises sobre o jornalismo e a comunicação não bastam. É preciso ir além, e de fato "meter a mão na massa", realizando capacitações e cursos de aprimoramento que viabilizem uma experiência prática do fazer jornalismo nestes novos contextos. Nesse sentido, fomentar parcerias entre instituições de ensino e empresas e demais organizações de comunicação, avançando em um processo de educação corporativa por um lado e de educomunicação por outro, poderiam ser alternativas viáveis para sanar estas demandas surgidas nos últimos anos. Tais iniciativas, além de oferecerem saberes práticos e contextualizados, iriam fomentar mais pesquisas e análises no campo do jornalimo.

0 que pretende-se, afinal, é asseverar que não é possível pensar, praticar e ensinar jornalismo se não estivermos conscientes das lacunas entre as realidades acadêmica e mercadológica. Faz-se necessário também estarmos atentos às múltiplas identidades do jornalista contemporâneo e suas atuações em diversos setores, com habilidades e competências. Isso sem deixar de lado a parte crítica e teórica as quais as instituições de educação não podem abrir mão por suas vocações históricas e culturais. As universidades e, especificamente, os cursos de jornalismo localizados em todo o país, não podem se permitir 
um preparo de profissionais com foco somente voltado para as redações jornalísticas: as vagas neste setor são cada vez escassas. Projetam-se, em perspectiva renovadora, oportunidades para os profissionais da área, oferecidas na denominada "mídias das fontes" e legadas ao gerenciamento de redes sociais e atividades ligadas à internet. Essas mudanças estruturais estimulam uma provocação para os professores, relacionada à questão a ser respondida em pesquisa e texto posteriores. Todavia, a questão a que devemos refletir, enquanto mediadores entre o conhecimento e os estudantes, é se estamos preparados para tal desafio.

\section{Referências}

ADGHIRNI, Z. L.; PEREIRA, F. H. Mudanças estruturais no Jornalismo: alguns apontamentos. In: Encontro Nacional de Pesquisadores em Jornalismo, 2010, São Luis. Anais... São Luis: Universidade Federal do Maranhão, 2010. Disponível em: <http://www.sbpjor.org.br/sbpjor/resumod.php?id=1006>. Acesso em: 23 dez 2013.

BOURDIEU, P. 0 poder simbólico. Rio de Janeiro: Betrand Brasil, 2012.

BOURDIEU, P. Sobre a televisão. Rio de Janeiro: Jorge Zahar, 1997.

BRASIL. Decreto-lei no 972, de 17 de outubro de 1969. Dispõe sobre o exercício da profissão de jornalista. Brasília, 17 out. 1969. Portal da legislação: governo federal. Disponível em: <http://www.planalto.gov.br/ccivil_03/decreto-lei/Del0972.htm>. Acesso em: 14 abr. 2016.

BRASIL. Ministério da Educação. Resolução no 1, de 27 de setembro de 2013. Institui as Diretrizes Curriculares Nacionais para o curso de graduação em Jornalismo, bacharelado, e dá outras providências. Diário Oficial [da] União, Brasília, 1 out. 2013. Seção 1, p. 26.

CAVALCANTI, J. R. No "mundo dos jornalistas": interdiscursividade, identidade, ethos e gênero. Tese (Doutorado) - Programa de Pós-Graduação em Linguística, Universidade Estadual de Campinas, São Paulo, 2006.

FERREIRA, G.; CARVALHO, C. Jornalistas Assessores de Imprensa: a tensão entre os campos da comunicação e da informação e a configuração do processo produtivo da noticia. In: Colóquio Internacional Mudanças Estruturais no Jornalismo, 1., 2011, Brasília. Anais... Brasília: Programa de Pós-Graduação em Comunicação da Universidade de Brasília, 2011. Disponível em: <www.mejor.com.br>. Acesso: 24 mar. 2014.

FIGARO, R. (Coord.). As mudanças no mundo do trabalho do Jornalista. São Paulo: Atlas, 2013.

GREENWOOD, E. Attibutes of Profission. Social Work, 1957. 
HUGHES, Everett C. Professions. Daedlus, [S.l.], v. 93, n. 4, p. 655-668, 1963.

LOPES, F. L. A institucionalização do mercado noticioso e seus significados para a construção da identidade do jornalista no Brasil. Estudos em Jornalismo e Mídia, v. 6, n. 2, p. 61-74, jul./dez. 2009. Disponível em: <https://periodicos.ufsc.br/index.php/jornalismo/article/.../1984.../11277>. Acesso: 01 abr. 2014.

LOPES, M. I. V. de. O campo da comunicação: institucionalização e transdiciplinação. In: LOPES, M. I. V. de et al. (Orgs.). Comunicação e informação: identidades e fronteiras. Recife: Bagaço; São Paulo: Intercom, 2000. p. 41-56.

MARCONDES FILHO, Ciro. Comunicação e jornalismo. A saga dos cães perdidos. São Paulo: Hacker Editores, 2002.

MARCONDES FILHO, Ciro. O fim do jornalismo Crítico? Novas Diretrizes Curriculares criam um abismo entre teoria e prática. Revista Cult, São Paulo, v. 17, n. 188 mar. 2014.

MICK, J.; LIMA, S. Perfil do jornalista brasileiro: características demográficas, políticas e do trabalho jornalístico em 2012. Florianópolis: Insular, 2013.

OLIVEIRA, R. M. de S. 0 impacto da internet no jornalismo: características e Recomendações para a concepção de jornais digitais Interativos. Dissertação (Mestrado em Engenharia de Produção) - Programa de Pós-Graduação em Engenharia de Produção e Sistemas, Universidade Federal de Santa Catarina, Florianópolis, 2001.

RUBLESCKI, A.; SILVA, A. R. da. Jornalismo líquido: tendência de ampliação do Campo. Brazilian Journalism Research, Brasília, v. 8, n. 1, p. 118-132, 2012.

SANT'ANNA, Francisco. Mídia das fontes: o difusor do jornalismo corporativo. Brasília: Casa das Musas, 2008.

SILVA, Rafael P. Ethos, discurso e identidade profissional do jornalista em assessoria de comunicação. Dissertação (Mestrado em Comunicação) - Programa de Pós-graduação em Comunicação, Universidade Federal de Juiz de Fora, Juiz de Fora, 2015.

SILVA, Rafael P. O Ciberespaço como lugar para o jornalista. In: Congresso de Ciências da Comunicação na Região Sudeste, 17., 2012, Ouro Preto. Anais... Ouro Preto: Intercom, 2012.

SOARES, Ana Thereza; MONTEIRO, Luisa da Silva. 0 contexto das organizações: uma leitura sobre suas configurações e seus processos comunicacionais. In: OLIVEIRA, Ivone de Lourdes; LIMA, Fábia Pereira (Org). Propostas conceituais para a comunicação no contexto organizacional. Rio de Janeiro: Senac Rio, 2012.

TRAQUINA, Nelson. Teorias do Jornalismo: a tribo jornalística. Uma comunidade interpretativa transnacional. Florianópolis: Insular, 2008. V. 2. 


\title{
Structural changes and journalism education: The teacher's role in the new direction of Brazilian journalism.
}

\begin{abstract}
Modern journalism is reshaped by changes in the production and circulation of news, in parallel, we have the technology integration and media convergence. At the same time, we have an extension of intertwining field activities and skills of professionals. Thus, the article reflects on the challenges and the role of teachers and journalism courses in this scenario. The methodology used a literature review based on studies on the ethos and journalistic habitus from the perspective of Traquina, Bourdieu and Cavalcanti, associated with supporting interviews conducted between 2011 and 2014 with two groups of journalists, one of them connected to the media traditional and the other to the press offices. Among the considerations, there is the need to think, teach and practice journalism consciously avoiding the gap between academics and market aspects and encouraging the promotion of awareness as evidenced by the multiple identities of the contemporary journalist, wrapped in skills and diversified skills.
\end{abstract}

\section{Keywords}

Education. Journalism. Ethos. Habitus.

Recebido em 27/08/2015

Aceito em 29/03/2016 